\title{
Catchments of general practice in different countries- a literature review
}

Donald P Allan

\begin{abstract}
The purpose of this paper is to review the current research on catchment areas of private general practices in different developed countries because healthcare reform, including primary health care, has featured prominently as an important political issue in a number of developed countries. The debates around health reform have had a significant health geographic focus.

Conceptually, GP catchments describe the distribution, composition and profile of patients who access a general practitioner or a general practice (i.e. a site or facility comprising one or more general practitioners). Therefore, GP catchments provide important information into the geographic variation of access rates, utilisation of services and health outcomes by all of the population or different population groups in a defined area or aggregated area. This review highlights a wide range of diversity in the literature as to how GP catchments can be described, the indicators and measures used to frame the scale of catchments. Patient access to general practice health care services should be considered from a range of locational concepts, and not necessarily constrained by their place of residence. An analysis of catchment patterns of general practitioners should be considered as dynamic and multi-perspective. Geographic information systems provide opportunities to contribute valuable methodologies to study these relationships. However, researchers acknowledge that a conceptual framework for the analysis of GP catchments requires access to real world data. Recent studies have shown promising developments in the use of real world data, especially from studies in the UK.

Understanding the catchment profiles of individual GP surgeries is important if governments are serious about patient choice being a key part of proposed primary health reforms. Future health planning should incorporate models of GP catchments as planning tools, at the micro level as well as the macro level, to assist policies on the allocation of resources so that opportunities for good health outcomes for all groups within society, especially those who have been systematically denied equitable access, are maximised.
\end{abstract}

Keywords: General practice catchment areas, Accessibility measures, GIS, Spatial scale, Markets, Primary health care, Patient registration catchments

\section{Introduction}

\section{Primary health care as an important issue in different} countries

Healthcare reform, including primary health care, has featured prominently as an important political issue in a number of developed countries. For example, in the recent USA presidential elections, the debate around the Patient Protection and Affordable Care Act (PPACA), also known as Obamacare, was intense [1]. In the United

\section{Correspondence: dpallan@adam.com.au}

Discipline of Public Health, School of Health Sciences, Faculty of Medicine, Nursing \& Health Sciences, Flinders University, Health Sciences Building, Registry Road, Bedford Park, SA 5042, Australia
Kingdom, ongoing debate in the UK National Health Service (NHS) centres on the role of general practitioners (GPs) not only as providers of primary care, but as procurers of secondary (hospital) care [2]. In Australia, reform of the primary health care sector, including the introduction of Medicare Locals, was a key strategy in the Labor Government's reform program, which has been subsequently shelved by the incoming Liberal Government [3,4]. In Switzerland, in June 2012, the Swiss voted against a new health initiative by the Government to control cost inflation, and address the challenges posed by population aging, chronic disease, and the cost of new technology [5]. 
The debates around health reform have had a significant health geography focus. For example, in the USA, the prestigious Institute of Medicine on behalf of the Affordable Care Act, published a report entitled "Variation in Health Care Spending: Target Decision Making, Not Geography" [6]. This report was perceived by a number of commentators as criticizing the work of the Dartmouth Institute for Health Policy and Clinical Review, which had advocated, through its Dartmouth Atlas of Healthcare, over many years that geography is important and that a geographic focus on health reform is strong $[7,8]$. In the UK, it is claimed that reforms envisaged by the Conservative Government, if implemented will have profound geographic implications on primary care [9]. In Switzerland, it was argued that the proposed reforms would create a two tier system with regard to general practice choice [5]. Within these debates, equity of access to primary health care services is an important issue [10]. General practice is considered an important part of the primary health care [11] and is more often considered to denote the first contact, accessibility, continuity and permanence of care provided in association with other sectors [12].

\section{The purpose of this review}

In the context of policy issues and debates around health reform, and specifically maximising access to primary health care, the purpose of this paper is to review the literature on private sector GP catchments in different countries over the past twenty five years. Conceptually, GP catchments describe the distribution, composition and profile of patients who access a general practitioner or a general practice (i.e. a site or facility comprising more than one general practitioner). Therefore the composition of GP catchments provide important information into the geographic variation of access rates, utilisation of services and health outcomes by all of the population or different population groups in defined local areas, or aggregated areas at higher spatial scale. Conceptual models of GP catchments, based on real empirical data, therefore have the potential as planning tools to assist health planners identify where opportunities for good outcomes have been systematically denied to groups within society and where access issues need to be addressed.

\section{Background to the review}

The background to this review originated from the development of case studies, using empirical data, of the catchments of private general practices in Australia, based on the model of the Practice Health Atlas [13]. Through the Australian Divisions of General Network, staff at the Adelaide Western Division of General Practice trained the staff in over 50 Divisions in the use of geographic information systems associated with the Practice Health
Atlas method. It is estimated that more than 500 case studies of individual general practices were produced through the Divisions. Unfortunately, to date, peer reviewed articles based on this important source of empirical data on the nature and composition of catchments of private general practices, including information from where patients access their general practice, have not been available.

\section{General practice catchments and primary health care policy in different countries}

The potential value of general practice catchments as a method to be used in small area health care studies, as a contribution to informed primary health care policy, prompted the development of this review of the international literature. The WHO defined the concept of primary health care as a strategy and a set of activities to reach the goal of "health for all by the year 2000" [14], however, since the Declaration, different schools of thought, and even confusion, as to the differences between selective primary health care, comprehensive primary health care and primary care, have evolved [15]. As Crooks and Andrews note, many governments have since created their own working definitions of primary health care [16]. The central attributes of primary health care, according to a literature review conducted by Maeseneer et al. in 2007 [17], are: first contact (accessibility), longitudinally (person-focused preventative and curative over time), patient-oriented comprehensiveness and coordination.

Primary health care can be provided by a range of health providers, including general practitioners (or physicians as they are referred to in the US, Canada, and often in the international literature), dieticians, nurses, nurse practitioners, occupational therapists, psychologists, physiotherapists, pharmacists, social workers, and other health care providers [18]. In this review, the term general practitioner and general practice are used throughout and include other similar used terms in different countries such as physician (not specialist physician as in the US), family physician and doctor. Further, the review narrowed and limited its focus to general practice (as one set of primary health care providers), and the attribute of accessibility, as one of the key attributes of primary health care because these concepts provided the central framework for the review of catchments of general practice.

\section{Catchments and access}

In the context of the review, the term catchment is assumed to mean a geographical area around the general practice that includes the client population which accesses its services [19]. At the outset of the review, no limitation was placed on the scale of the catchment, and therefore the scale might range from the local to the national, 
provided that there was a clear link between the provider of the service and the client population accessing the service.

There are many ways of thinking about access to primary health care. Crooks and Andrews [20] have noted that access is a topic of great interest to health geographers, and whilst geographic access to care is clearly overtly geographic, health geographers interest in access extends beyond this. They note that certain health professionals (e.g. general practitioners) serve as gatekeepers to people's access to secondary and tertiary care and given their centrality to primary health care in many countries, their practice (both spatial and non-spatial) plays an important role in people's access to primary health care.

A review of the literature on access to primary health care was conducted by Ansari [21] in 2007 who observed that whilst policy-makers are concerned about providing equal access to health care for all, there was a significant lack of detail in the plethora of policy documents regarding what is meant by the term "access". In the review, Ansari [22] found that the concept of access to health care has long been ill-defined, with no clear consensus on its definition in the literature and no universally accepted way to measure it. Ansari summarised the theoretical work of various researchers into a framework of access . The model of Penchansky and Thomas [23] is referred to by Ansari as a general model of access covering five dimensions of access which include availability, accessibility, accommodation, affordability and acceptability. Ansari then refers to the work of Donabedien [24] and Khan and Bhardwaj [25] who further sub-divide the accessibility dimension into two sub-categories, termed socio-organisational and geographic (Donabedian) and aspatial and spatial (Khan and Bhardwaj).

Recent writers have provided further perspectives on accessibility, spatial access and spatial equity of access in primary health care. For example, Wang [26] argues that spatial access emphases the importance of spatial separation between supply (i.e. health care providers) and demand (i.e. the population) and how they are connected in space and thus is a classic issue for location analysis. Wang suggests that in the USA, the main debate revolves around what are reasonable catchment areas (sizes) for general practices. As noted in the introduction, in the US, the Patient Protection and Affordable Care Act (known popularly as Obamacare) has generated controversy over measures to assess access to general practitioners. For example, the Manhattan Institute for Policy Research [27] has initiated an ongoing evaluation of the PPACA with an evaluation of the law's effect into five areas including access to care. The researchers noted that geographic maldistribution of health care resources is an important issue, but chose not to investigate it. Instead, they acknowledged that the issue of geographic maldistribution of health care resources has generated different explanations from variations in Medicare spending to differences in treatment intensity [28].

In the UK, Lewis and Longley [2] focus on the spatial equity of access to health systems, and this includes the question of who benefits and why in the provision of urban services and facilities. Lewis and Longley note that the proposed reforms in the UK, in their present state, would seek to abolish catchment areas.

In summary, the focus of this review paper therefore has a quite specific focus on the role of catchments of private sector general practitioners within primary health care. Catchments provide an area of study where the effects of government spending (such as the spending arising from the new Obamacare Law) and geographical variation in access to GP services can be studied together. A review into the literature on GP catchments in different countries is important because it should provide important perspectives on the nature of health care accessibility and therefore inform public policy debates on primary health care health care reform.

\section{The aims of the review}

Research questions on the review of the literature on catchments were formulated to incorporate the perspectives as outlined above.

This review aims to examine the existing literature in order to find out:

- How are GP catchments described and in what context?

- What indicators and measures are used in the description of catchments?

- What relationships between the health seeking behaviour of patients and GP catchments are studied in different countries?

- What relationships between the concept of a GP catchment and public health policy (including regulation) issues are studied in different countries?

The outcome of the review will include identifying areas where there are the gaps in the literature and suggesting areas of research worth further investigation.

\section{Method}

\section{Overview}

The goals of the literature review were to: (1) conduct a literature review of peer reviewed papers (titles or abstracts) with any mention of GP catchments in relation to primary health care; (2) identify from title or abstract, key words in relation to the term GP catchment that could facilitate further narrowing of the search; (3) to synthesise the articles into a number of broad themes in relation to the aims of the review. 


\section{Search strategy and selection criteria}

The search strategy was conducted in four stages. The first stage was a pilot stage, with a search of the database of the International Journal of Health Geographics (IJHG), which is a journal known to publish many peer reviewed articles within the theoretical framework. Using the key words "catchments in health", this search yielded 21 results. The search also included two previous literature reviews and their citation lists. One paper [29] had a primary focus on the methodologies used to examine access through Geographic Information Systems (GIS) approaches and the second [30] examined concepts, methods and challenges in spatial accessibility. An iterative approach involving key words identified in the literature reviews and in the peer reviewed papers from the initial search, was adopted to expand the search in the database of the IJHG and in the database of another journal, Social Science and Medicine. This search yielded a further 182 results.

This iterative process identified key words as relevant to the literature on catchments of general practice in primary health care. The key words included: Geographic Information Systems (GIS), catchments and markets in health, competition in primary health care markets, the Two Step Floating Catchment Area (2SFCA) method, spatial accessibility and primary health care; GIS and primary health. In the search, the term physician was recognised as meaning the same as the term general practitioner and it was therefore also included in the search.

The second stage of the search strategy was conducted through MEDLINE, using the databases of Web of Knowledge and PubMed. Google Scholar was used after the other searches were complete. The initial search began with the Web of Knowledge database using the key words: general practitioners and accessibility, covering all years and in the English language. This yielded 1,321 results and then further filtering was undertaken. The filters included:

General practitioners and accessibility and catchments ( $\mathrm{N}=42$ results);

General practitioners and accessibility and spatial accessibility ( $\mathrm{N}=14$ results);

General practitioners and accessibility and GIS ( $\mathrm{N}=14$ results);

General practitioners and GIS ( $\mathrm{N}=35$ results);

Accessibility and catchments in primary health

( $\mathrm{N}=156$ results);

Access and physician market areas ( $\mathrm{N}=95$ results);

General practitioners and accessibility and markets

$(\mathrm{N}=21$ results).

The process was then repeated with PubMed, using the key words: general practitioners and accessibility in order to cross reference the search in the Web of
Knowledge. The search yielded 908 results. A similar filtering process was then undertaken. In PubMed, the category of the Two Step Floating Catchment Area method was searched and this yielded 101 results. Total results prior to exclusion were 1,422 results.

The process of exclusion included eliminating articles by title or abstract if the article did not relate in any way to private sector general practice, general practitioners or physicians]. Peer review papers were selected and prioritised based on their inclusion of two or more of the key words in abstract: accessibility in primary health care, the concept of catchments or markets; private general practice; and preferably GIS concepts, methodology or terms. Prioritisation also included an assessment as to how the article rated overall to the search criteria. This meant that peer reviewed papers covering accessibility and one or more of the other access dimensions (e.g. the availability dimension) could be eligible for inclusion.

The third stage of the search process involved a quality audit, based on feedback received from independent reviewers. This process identified a number of relevant papers, where the term "general practice" or variation was not contained in the title, but where the context of the paper related substantially to one or more of the aims of this paper. This process identified another 12 papers for inclusion. A total of 102 peer reviewed papers were identified as relevant to the review. The search process is shown in Figure 1. The fourth stage involved an analysis of the title and abstract of each of the papers based on the criteria as shown in Table 1. The criteria for Table 1 was developed in the context of the aims of the review. The results of the analysis are also shown in Table 1.

\section{Results}

\section{Overview of the results of the search}

Table 1 shows the analysis of the journal articles in relation to the search criteria and the aims of the search. Using the title, abstract and key words, the articles were analysed by a number of categories consistent with the aims of the review. The analysis formed the basis of reviewing the articles in the context of the aims and the results are presented in the following sections.

There were 102 papers within the study. There were four literature reviews, one from 2004, one from 2005, one from 2007, and one from 2012. The papers were sourced from 10 different developed countries. There were a range of population groups referred to in the papers, ranging from non-specific neighbourhood or regional populations to specific disease population groups, or particular service needs groups, such as immigrants or out of normal hours population groups. Studies ranged from a spatial scale on the neighbourhood through to state and national. There were five different types or variation of catchment models identified, but the Two 


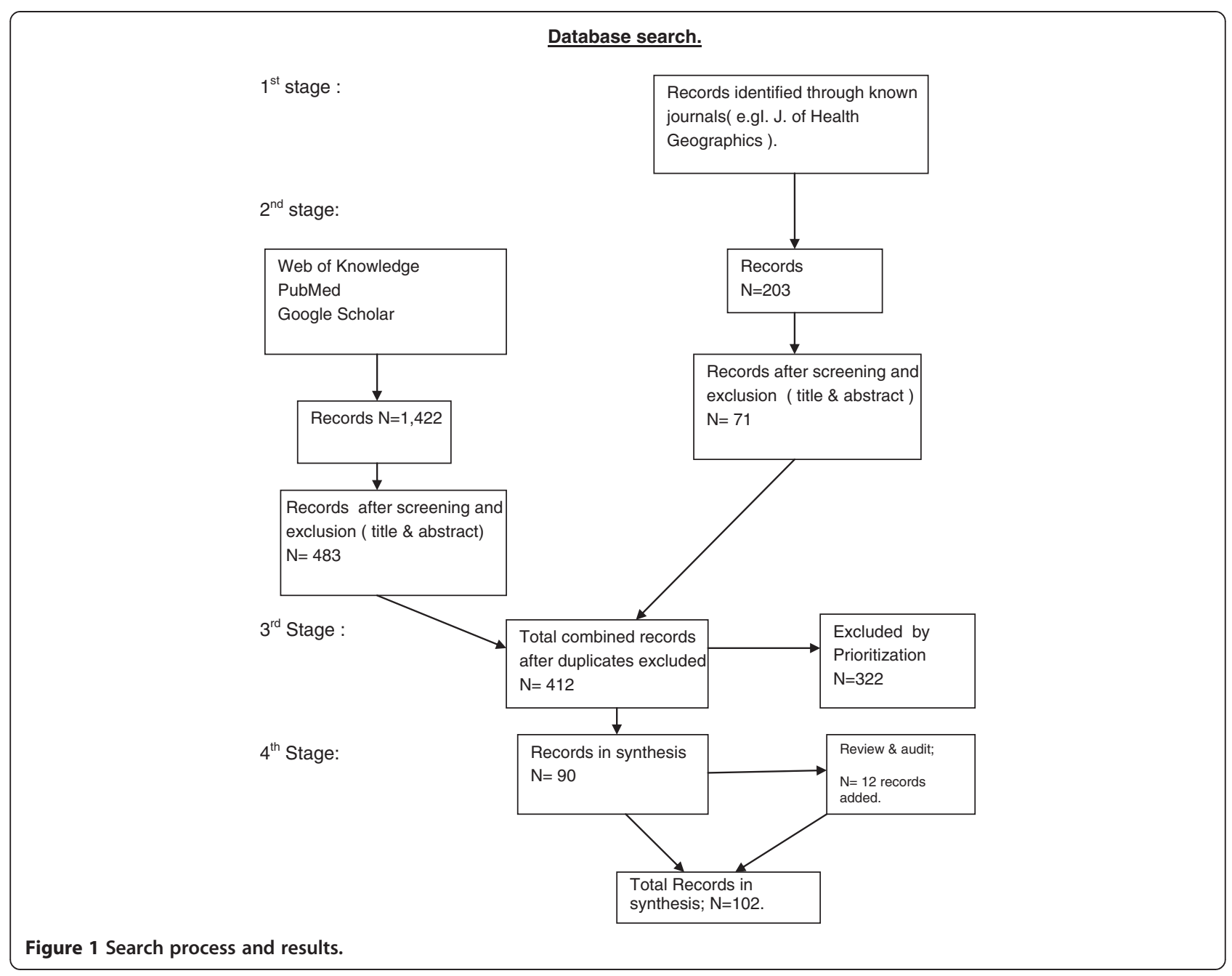

Step Floating Catchment Area model was the model most frequently used in the studies. Patient choice was identified as a common theme in the studies that related to the health seeking behaviour of patients in terms of access to general practitioners. Studies that explored the relationship of GP catchments and the policy framework of the state or national government illustrated the concerns that government intervention in the primary health care market would affect the economic decision making of private sector GPs, and their decisions about the scope and supply of their services to consumers.

\section{The results}

\section{Studies of GP catchments in relation to their description and context}

Overview In relation to descriptions of GP catchments, Table 1 shows that relatively few of the articles in the review contained the words "GP catchment" in their title. The search had to analyse the articles in the details of the abstracts and even the text of the articles to determine the context in which GP catchments were discussed. This lack of common framing of the term GP catchment in the journals has lead to the development of at least five different catchment models (Table 2). Four of these models have been based on empirical data and have attempted to describe what an actual GP catchment or group of catchments within a region might look like. In addition, a wide range of spatial scales, indicators, measures and data sources are used in conjunction with studies in relation to GP catchments (Table 1).

Theory From a theoretical perspective, two articles [31,32] reflect on the role of Central Place Theory in urban and rural planning. In Australia, Smailes argues that individuals can belong to a number of social catchments at different scales and the degrees of attachment people feel to various scales of attachments is an area of needed research. Hugo, Smailes et al. [31] define social catchments as the territory occupied by a group of households and individuals who are in some form of regular interaction and which the inhabitants identify as their community of interest. They question the meaningfulness of 
Table 1 Summary of results: the analysis of the studies in the review in relation to GP catchments

\begin{tabular}{|c|c|c|c|c|}
\hline Criteria & Category & Number & $\begin{array}{l}\text { Total number } \\
\text { in the category }\end{array}$ & $\begin{array}{l}\text { Percentage of } \\
\text { total studies }\end{array}$ \\
\hline \multirow{8}{*}{$\begin{array}{l}\text { What is the major theme in the article as } \\
\text { outlined in the title?: }\end{array}$} & Literature review & 4 & \multirow[t]{8}{*}{102.} & \multirow[t]{8}{*}{$100 \%$} \\
\hline & Measurement as the key theme in the research study. & 16. & & \\
\hline & Spatial access as the key theme & 30. & & \\
\hline & $\begin{array}{l}\text { The role of markets, and competition between } \\
\text { catchments of general practice, in primary health care. }\end{array}$ & 23 & & \\
\hline & $\begin{array}{l}\text { The Neighbourhood as the focus of the research } \\
\text { inquiry. }\end{array}$ & 10. & & \\
\hline & The role of patients choice as the focus of the study. & 9 & & \\
\hline & Studies in relation to access issues in primary health care. & 6. & & \\
\hline & Other issues of methods and scale. & 4. & & \\
\hline \multirow[t]{5}{*}{ What Spatial scales are applied in the article? } & Neighbourhood. & 9 & \multirow[t]{5}{*}{75} & \multirow[t]{5}{*}{$73.5 \%$} \\
\hline & Region/metropolitan & 36 & & \\
\hline & Rural & 10 & & \\
\hline & State/National & 10 & & \\
\hline & Multi-scale & 10 & & \\
\hline \multirow[t]{5}{*}{$\begin{array}{l}\text { What Indicators and measures \& data } \\
\text { sources are used? }\end{array}$} & $\begin{array}{l}\text { Socio-economic/demographic/Ethnicity/Census } \\
\text { data./population cohorts at regional, state, national } \\
\text { (inc postcode data) }\end{array}$ & 31 & \multirow[t]{5}{*}{75} & \multirow[t]{5}{*}{$73.5 \%$} \\
\hline & Patient registrations./lists/retail clinics & 9 & & \\
\hline & $\begin{array}{l}\text { Multiple/various (Including Medicare data, other health } \\
\text { care data. }\end{array}$ & 20 & & \\
\hline & Observational studies/cohorts/surveys & 5 & & \\
\hline & Other large data sets - GP workforce data sets & 10 & & \\
\hline \multirow{2}{*}{$\begin{array}{l}\text { What are the GIS methods, if any, applied } \\
\text { in the paper }\end{array}$} & 2 SFCA method & 26 & \multirow[t]{2}{*}{43} & \multirow[t]{2}{*}{$42.1 \%$} \\
\hline & $\begin{array}{l}\text { Other methods of GIS (including those referenced } \\
\text { in Table 2) }\end{array}$ & 19 & & \\
\hline \multirow{7}{*}{$\begin{array}{l}\text { What specific Population cohorts, if any, } \\
\text { were used in the study? }\end{array}$} & Elderly & 2 & \multirow[t]{7}{*}{32} & \multirow[t]{7}{*}{$31.4 \%$} \\
\hline & Ethnic groups & 2 & & \\
\hline & Rural & 7 & & \\
\hline & Immigrants. & 4 & & \\
\hline & Urban/Neighbourhoods & 14 & & \\
\hline & People with disabilities & 1 & & \\
\hline & Out of hours groups & 2 & & \\
\hline \multirow{7}{*}{$\begin{array}{l}\text { What Access issues/Primary health care } \\
\text { were referred to in the paper? (including } \\
\text { non-spatial factors) }\end{array}$} & Reform/politics & 14 & \multirow[t]{7}{*}{77} & \multirow[t]{7}{*}{$75.5 \%$} \\
\hline & Workforce & 10 & & \\
\hline & Spatial equity/Accessibility/Access to care & 20 & & \\
\hline & Patient choice/consumers/registration & 7 & & \\
\hline & Health inequalities & 12 & & \\
\hline & Socio-organisational/Practice characteristics & 7 & & \\
\hline & Access to retail clinics & 5 & & \\
\hline \multirow[t]{5}{*}{ What was the country of origin of study } & USA & 35 & \multirow[t]{5}{*}{102.} & \multirow[t]{5}{*}{$100 \%$} \\
\hline & Canada & 6 & & \\
\hline & UK & 17 & & \\
\hline & France & 5 & & \\
\hline & Switzerland & 3 & & \\
\hline
\end{tabular}


Table 1 Summary of results: the analysis of the studies in the review in relation to GP catchments (Continued)

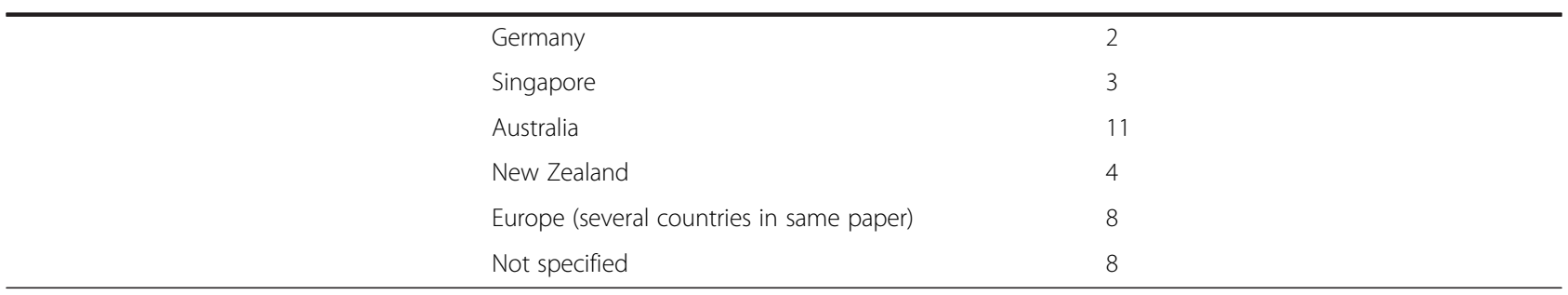

(Analysis by: title, abstract and key words).

administrative boundaries for planning purposes and instead advocate research to develop a nested hierarchy of social catchments for social, economic and community planning in non-metropolitan areas. Hugo, Smailes et al. used the catchments of general practice in rural Australia to illustrate their arguments. Since 2000, there seems to have been a lack of theory application in regard to studies of catchments. For example, as Root notes [33], huge bodies of geographic theory on the modifiable areal unit problem (MAUP) and the relevance of scale have all but been ignored.

Examples of GP catchment models Table 2 outlines examples of catchment models as developed in different countries. Each model has been developed in the context of the primary health care policy of the different country and the role that GPs fulfil in providing primary health care services within the overall policy framework.

In North America, as Shortt et al. note [34], the free market economy dominates and this results in greater patient choice and increased competiveness between health services. However, previous methodologies have been based on the importance of competing health care institutions in the secondary care market, at the expense of the primary care sector. Data on private sector GP catchments is thus considered as commercial -inconfidence and highly valuable. Models in the US have

Table 2 Examples of catchment models of general practice in different countries

\begin{tabular}{lll}
\hline Model & Definition & Health example \\
\hline Two Step Floating Catchment Area & A special case of the gravity model, using a special & It measures spatial accessibility to primary care \\
method. (and enhanced 2SFCA & form of the physician to population ratio. The & physicians. \\
method) (2000, 2003, 2009) USA. & $\begin{array}{l}\text { enhanced 2SFCA method addresses the problem of } \\
\text { uniform access within the catchment by applying }\end{array}$ & $\begin{array}{l}\text { It reveals spatial accessibility patterns more consistent } \\
\text { weights to different travel time zones to account for }\end{array}$ \\
& $\begin{array}{l}\text { wistance decay. } \\
\text { professional shortage areas. }\end{array}$
\end{tabular}

Synthetic Data Matrix (SDM, 2005) C Compares patient to GP flow (affiliation) information Northern Ireland data.

Practice Health Atlas method. (PHA, 2006, 2010) Australia.

Local Potential Accessibility (LPA) measure. (2012) France.

Lewis \& Longley Model (2012) England. aggregated at the Census Enumeration District level across a number of catchment areas using different methodologies. The SDM is then analysed using a modified version of the European Regionalisation Algorithm to create an optimal set of non overlapping regions according to predefined population size and self-containment criteria.

Provides catchment maps of patients of individual general practices, based on post code place of residence. Maps patient catchments in 7 chronic disease categories. Details level of utilisation of health services and documents level of health outcomes for specific disease groups. Describes the general practice market share of each individual postcode within a region.

The LPA indicator measures the supply and demand for general practice services by taking into account practitioners' volume of activity on the one hand, and service use rates differentiated by population age structure on the other.

An analysis of a data set, derived from the National Health Service Central Register. The Model compares the observed patient registrations at GP surgeries with an optimum geographic pattern.

The Model also uses a new ethnicity classification tool to assess the ethnic dimensions to deviations from the normative arrangement.

\section{General practices within a defined health region.}

General practices within a defined health region. The PHA has the capability to measure individual catchments or aggregated catchments at city or regional level.

The LPA indicator to private GPs indicator reveals a greater degree of variability than the traditionally used accessibility indicators (travel time, level of GP density in living areas ...)

From the London borough of Southwark. The has a focus on spatial equity of access.

The Model maps the role of the GP surgery as a place that provides local services in away that tries to serve the population as a whole (spatial equity). 
been developed using either Medicare, Medicaid data or related public health data, or aggregate data about the numbers of GPs and the population in defined areas as in the case of the Two Step Floating catchment Area model. Specific examples of private sector GP catchments or groups of catchments could not be identified.

In Northern Ireland, Shortt et al. [35] reported there was a lack of sophistication in the definition of medical service areas and that a new methodology needed to be developed. Shortt identified that GP catchment areas, though an essential basis for providing GPs with important information such as levels of accessibility to surgery, were rarely or clearly accurately defined. Previous definitions of GP catchments had been defined to single regionalisation methods, such as mean distance measures, which were prone to overestimation or underestimating medical service areas.

To address these shortcomings in the description of GP catchments in Northern Ireland, Shortt et al. developed a technique involving the creation of a Synthetic Data matrix (SDM) which compared patient to GP flow (affiliation) information aggregated at the Census Enumeration District level across a number of catchment areas using different methodologies. The SDM was then analysed using a modified version of the European Regionalisation Algorithm to create an optimal set of non-overlapping regions according to pre-defined population size and self containment criteria. In policy terms, as Shortt argues, the benefit of optimal catchments lies in their discrete nature (in terms of boundaries) and their applicability for detailed locality planning and resource allocation [35].

In England, Lewis and Longley [2] developed an analysis of a previously unexploited data set comparing the observed pattern of patient registrations at GP surgeries with an optimum geographic pattern in the London borough of Southwark. The research by Lewis and Longley represents an important breakthrough in the development of a conceptual framework of GP catchments because they were able to map the actual percentage of patients using the nearest GP surgery. In addition, through their analysis, they were able to profile the population characteristics within the catchment. From this analysis, they were able to identify the role of the GP surgery as a place of importance as it provides local services in a way that tries to serve the population as a whole (i.e. spatial equity). Longley and Lewis argue that understanding the catchment profile of individual GP surgeries is important if the National Health Service (NHS) is serious in its mantra about patient choice being a key part of its proposed reforms.

In Australia, the development of the Practice Health Atlas [13] offered some similar potential. The Practice Health Atlas (PHA) requires access to real patient data of the general practitioner, de-identified, to provide a catchment map of the percentage of patients, at the post code level. The PHA maps patient catchments in 7 chronic disease categories and it provides details of the level of utilisation of health services and level of health outcomes for specific disease groups. The PHA identifies the general practice market share of each individual postcode within a region. It includes a service substitution model which details the optimal level of services that a general practice could be providing to its patients; ie. the gap between actual services and potential. The PHA also models how the practice can substitute services from a general practitioner to a nurse, thereby enhancing the capacity of the practice to increase its utilisation of services for patients. The advantage of this data level analysis is that it removes the need to make theoretical assumptions of patient travel time of the general practice. It also provides strong data on consumer preference, such as the percentage of patients who might be accessing the practice based on their work location rather than residential address. The Practice Health Atlas was adopted extensively by Divisions of General Practice in Australia to assist general practices. Since 2011, Divisions have been replaced by Medicare Locals, and very little research using PHA data has been published in the peer reviewed literature.

In France, the Local Potential Accessibility [36] measure, offers alternative ways of assessing general practitioner provider to patient population accessibility measures. The Local Potential Accessibility (LPA) requires access to general practitioners' volume of activity on the one hand, and service use rates differentiated by population age structure on the other. As Bartlet et al. explain, the new indicator permits reviewing data concerning the differences in medical services density and access to care between urban and rural areas. Traditionally, as they explain, spatial accessibility to GPs has used density of GPs and travel distance to the nearest GP. However, this does not take into account the number of accessible GPs. The density indicator provides aggregated healthcare supply available in a given area, but has the inconvenience of not taking into account interactions with neighbouring geographical areas. GP density thus ignores population movements across administrative boundaries, even though they are frequent for small geographic areas. The LPA attempts to offset these limitations by calculating an indicator for each municipality taking into account supply and demand within the municipality and neighbouring municipalities.

Recent articles [37-40] continue to question methodologies based on administrative units. The articles advocate the need to reconceptualise the concept of place based perspectives in general practitioner health services and invoke the need to explore the theoretical contributions of time geography and spatial ecology as opportunities to integrate human agency into contextual models of health. 
In summary, more journal articles that produce examples of actual GP catchment profiles at either the individual, local, or group level are required so that a conceptual framework of GP catchments, as they are currently configured in different countries, can be established. Without practical examples of GP catchments, then the debate on health reform and how to allocate resources remains largely controlled by those groups or vested interests who benefit from the current status quo, and such a situation is unlikely to address issues of spatial inequality to health care.

\section{Studies of GP catchment areas and related indicators, measures and models}

From Table 1, it can be seen that studies in relation to GP catchments ranged in spatial scale. A nomenclature, such as a neighbourhood, local area, region, an administrative unit, out-of-hours area or a specific disease population group, is often used to describe such an area. They are place based studies.

Neighbourhoods There were twenty nine articles [33,34,36-61], of which the vast majority were published since 2004, where the focus of the general practice primary health care study related to geographic unit of size. Of these, fifteen [33,36-38,41-51] had a specific focus on primary health and the neighbourhood as the unit of size. Within the fifteen articles, the themes included inequality, ethnicity and cultural diversity, socio-economic factors, rural health, the built environment, the role of spatial and aspatial (social) factors and even local traffic conditions. A range of methodologies of analysis were used, including GIS (Two Step Floating Catchment Area method), individual in-depth interviews, a community resilience model incorporating spatial analytic strategies, asymmetric spatial modelling, and social modelling of cultural groups.

The unit of measurement to define neighbourhoods also varied from administrative units (such as collection districts requiring a geographic spatial scale) to the "inner characteristics" of a neighbourhood or the neighbourhoods' idiosyncrasy [48]. Lebel et al. make the observation that the neighbourhood integrates place as well as people and therefore its conceptualisation must consider characteristics of both place and people, and the interaction between them. It must also consider that a neighbourhood is always part of a larger area [48]. A multi-dimension concept of neighbourhoods is recommended by Lebel in the study of health inequalities. Lebel argues that the method could be used in urban and rural areas, leading to a possible new perspective on the nature of neighbourhoods in rural areas. Natural neighbourhoods as compared to administrative or census tracts, using a variation of the Two Step Floating Catchment Method was also reported by Bissonnette et al. [44] with implications for identifying intra-variations in access to health care. McGrail and Humphreys [58], on the other hand, developed a new index of access to rural primary care services using the Two Step Floating Catchment Area method and service health data using collection districts. Odoi et al. [49] studied neighbourhoods, which they defined as being the same as census tracts, and they used multivariate techniques (principal component analysis - PCA) to characterise neighbourhoods as units of analyses in investigating equity in health status, access and utilisation of health services. Odoi argues that a "onesize-fits all” planning approach is neither efficient nor practical and that planning strategies based on single variable analysis may not be appropriate since the strategies would not be tailored to the unique characteristics and needs of neighbourhood types.

Catchments and specific populations There were seven articles reviewed, of which five of the articles [52,54-57] identified issues of spatial inequality for cultural minorities at the neighbourhood level in accessing physician health care. The studies incorporated the Two Step Floating Catchment Area method along with other methods, such as questionnaire surveys or probability studies. There were two articles $[60,61]$ on out of hours care and patient populations. The method of analysis included survey data in one article [60], but the use of patient call out service data in the other. The analysis of catchment areas varied with one [61] using an area level index to measure rurality and in the other, there was an absence of strictly defined catchments areas. In the first study, differences were in service usage identified due to the factors of deprivation and distance (including differences between rural and urban areas), and in the second, higher representation of certain socio-economic groups, but this could have been due to these patients coming from broader catchment areas.

In summary, this section has outlined the wide range of ways in which GP catchments have been incorporated into the literature. However, the diversity of descriptions and use of a wide of indicators may not be helpful in clarifying the issues in the political debate over the allocation of resources to primary health care in periods of fiscal restraint. Greater uniformity and use of common terms, based on empirical studies, would assist the development of political arguments to advocate on behalf of those in need.

\section{Indicators and measures using geographic information systems (GIS) methodology}

Developments in geographic information systems (GIS) methodology have enabled a surge in the number of studies exploring the distribution of, and accessibility of health service providers to primary care populations. Two previous literature reviews, Guagliardo [30] in 2004 and Higgs [29] in 2005, have described and explained 
key issues, concepts and measurements of spatial accessibility of primary care. A further methodological review on measurement, optimization and impact of health care accessibility was published by Wang [26] in 2012 .

The three reviews recognise that access to healthcare has multiple definitions. Guagliardo argues that this has lead to confusion in distinguishing between the ability to get care, the act of seeking care, the actual delivery of care and related indicators. The articles cite various definitions of access, but judge potential accessibility and revealed accessibility as key issues. Each article recognises a number of barriers which can impede progression from potential to realised access. These barriers, first identified by Penchansky and Thomas [23], include: availability, accessibility, affordability, acceptability and accommodation. Availability and accessibility are spatial in nature and this is where studies using GIS have focussed. Guagliardo coins the term spatial accessibility for such studies and identified most published measures of spatial accessibility to health in four categories: provider to population ratio; distance to nearest provider; average distance to a set of providers; gravitational models of provider influence.

In describing recent developments in the use of GIS methodology, each of the reviews [26,29,30] single out the Two Step Floating Catchment Area (2SFCA) method as an important new development as a method of measuring GP to population ratios, and identifying areas of GP workforce shortage. The 2SFCA method is described and critiqued in the articles. Higgs [62] describes the 2SFCA method as a relatively sophisticated technique that accounts for interactions between patients and general practitioners across administrative boundaries by evaluating accessibility as the ratio between supply and demand, both of which are determined within travel time catchments. In the first step, as described by Higgs, a travel time catchment is computed around each supply point (e.g. a primary healthcare practice) and its estimated population count utilised to calculate a GP to population ratio. In the second step, travel time catchments are computed around each demand centre (e.g. a population weighted centroid) and accessibility to service provision is measured by summing all general practitioner to population ratio values contained in the zone. The final accessibility measure reports the balance between doctor availability (ie general practitioner to population ratio) and service accessibility (sum of all supply points lying within a given travel time of the demand centres), returning higher values as accessibility increases.

Since the enhanced 2SFCA method was developed by Luo and Wang, the number of studies [26,50,55-58,63-82] using the methodology, or referring to the methodology, is more than any other specific GIS methodology. In this review twenty six studies were identified since 2004 that have applied the 2SFCA method to measure spatial accessibility. Wang in his 2012 review provides a comprehensive coverage of the papers, and includes other papers, notably in the USA, that have explored and fine tuned the 2SFCA method [26]. A common theme in the studies included the application of the 2SFCA method to measure spatial accessibility and to identify areas with a shortage of general practitioners. Some studies [50,55-58,65-68,71] combined other factors such as socio-economic factors or ethnicity to the 2SFCA to identify specific low areas of access to general practitioners. Studies included areas within metropolitan areas, a region, a state or even a nation state.

Limitations in the strength of the 2SFCA method are acknowledged by reviewers and even advocates of the method. For example, as Guagliardo notes [83], it is intuitive that communities located at insurmountable distances from any source of healthcare will be negatively impacted by the lack of resources. Both Guagliardo [83] and Higgs [62] note that critics have commented that daily activity spaces, such as where patients work, may be more representative of an individual's location than residential address. All three reviews recognise that a key limitation in modelling is the lack of available empirical data on "real" health service access behaviour and its relationship to geography. The 2SFCA method, as McGrail [63] notes, requires assumptions of catchment size, distance-decay and the variable application of the variable application of these across metropolitan and rural populations, but to date, many applications of the 2SFCA method have not been verified against empirical access behaviour data. Wang [26] notes that the increasing complexity of the accessibility models hinder their implementation and adoption by health professionals. Wang also notes [26], the main debate centres on what are reasonable catchment area sizes for general practitioner services, but that the debate as to what is the right size for catchment areas cannot be settled without real world data. Other studies [75,76,81,82,84-86] have explored a range of measures using GIS methods at the regional or larger scale to develop stronger evidence based methods to assist in health planning.

In the US, Root [33] has been also critical of geographic information systems tools, arguing that the analysis has not been particularly sophisticated, and that huge bodies of geographic theory on the modifiable areal unit problem (MAUP) and the relevance of scale have all but been ignored. However, Taylor et al. [87] argue that the use of GIS as a tool to determine where clinics can be placed to maximise access to care is particularly relevant for primary care services associated with ongoing changes to the health system, especially in light of the Patient Protection and Affordable Care Act 2010. The study by Taylor et al is important because it demonstrates a way in which GIS 
can be used for administrative decision-making at the local public health level. Using empirical data, the researchers were able to model primary care centre locations and patient residences within a six mile catchment. This enabled the decision-makers to consolidate the number of centres with no or minimal changes to patient travel distances. One of the limitations acknowledged by the researchers was that using patient residences may be a limitation given that some patients travel from their workplaces or schools to the nearest primary care centre.

In summary, the use of geographic information systems has developed significantly over the past ten years, but there remains considerable scope for the use of GIS to critically analyse and model the scale and composition of GP catchments in the future.

\section{Studies of GP catchments and the health seeking behaviour of patients}

In relation to the third aim of the review, consumer choice and preference in the selection of primary care general practitioner is explored. Nine articles [88-96] focussed on how and why consumers either changed general practitioners or by-passed local primary care general practitioners. In the US, one study [88] found that overall $32 \%$ of respondents bypassed local primary care. A common theme in the articles [88-96] is that selection of a general practitioner is a deliberate choice process, the extent of information available about the practice is a factor, and that customer satisfaction is important. Direct accessibility to health services, as compared to the gate-keeping role of GPs, was important in one study [94] which included 14 European countries.

The health seeking behaviour of patients has also been revealed in articles about changes in the market and GP response to providing services in regard to consumer choice. Twelve articles [96-107] explore issues in the supply of general practitioner services to population groups in different types of markets in different countries. A common theme is that the supply of general practitioner services is changing in response to changes in the market, which may be as a result of government intervention, consumer preferences or other factors. Three articles [104-106] describe the growth and characteristics of retail health clinics in the USA. The articles note that the retail clinics, whether they are catering for ignored markets or new innovations, are siphoning patient care visits away from primary care general practitioner because of their attention to quick access, affordable prices and consumer-friendly approaches. Typically, the retail clinics cater for populations within a 5 minute driving distance, much less than the assumed driving distances in established GIS catchment models such as the 2SFCA method. The articles note that retail clinics may disrupt a number of aspects of existing primary care, including the range of services as well as market share of catchments. Another article [101] from the USA identifies that primary care general practitioners need to adopt different strategies according to the market in which they operate. The article notes the changes in market dynamics since 2004, which include the changes in employment contractual arrangements, business models and the percentage of primary care general practitioner employed in large delivery health systems (changed from 20 per cent in 2004 to over 40 per cent in 2012). The article identifies three different types of markets and advocates that general practitioners need to consider broader system goals in order to identify the right primary care strategy.

In summary, the consumer voice and choice in research studies as to their perceptions of GP catchments within the context of the relevant health market is an important area for study. The above articles highlight that consumers do not necessarily choose the nearest general practice to their place of residence when choice is available in the market. The relationship of GP catchments within the relevant health market and consumer expectations of what they expect of primary health care services needs more critical analysis.

\section{Studies of GP catchments in relation to issues of primary health policy and regulation}

There were twenty papers [98-100,108-124] that explored the role of government in regulating or changing the primary care health service. A common theme of the articles relates to the role of government intervention as to whether it is seen as a desirable legal regulatory control or a distortion of market forces in the allocation of health resources. For example, in England, the articles [110-114] explore the ideology of the government in creating local competitive markets comprising state, private and not-forprofit providers (with an independent regulator), based on the premise that a new primary care market should break the general practitioners' monopoly of the provision of primary care and increase choice for consumers. Some of the articles note that there is significant uncertainty as to whether the policy will deliver desired objectives. Since 2012, government legislation has resulted in further changes in general practitioner markets [114].

Similar themes are covered by articles from Norway, Holland, and Germany and in articles in the USA $[115,116,119]$. Gingrich [107] synthesizes what is known about markets within the welfare states of Europe and England. Markets, according to Gingrich in an analysis of social services including primary health care, schools and long term care, vary across policy areas and countries. Government policy therefore, Gingrich summarises, has a strong influence on the types of markets that exist and evolve in primary health care settings. Policy changes alter who has control over production (ie. state/users/producers) 
and how resources are allocated and accessed, resulting in different welfare outcomes within these markets and general practitioners ' share of the market.

The relationship between the concept of a total market for GP services and the catchments of individual GPs or general practices within the overall market requires further study. Several large scale studies, such as those of Busato [100] in Switzerland and McRae [98] in Australia have explored aspects of the GP supply of services within the overall market and the implications for patients wishing to access a GP. Both studies have implications for governments wishing to control the supply of GP services in a financial environment of cost cutting measures. For example, McRae showed if the Medicare rebate increases, GPs do not need to see as many patients to achieve the desired level of income. Busato [100] argues that freezing the number of general practitioners may have only a very limited effect on the associated resource utilisation.

In summary, studies from a number of countries show that changes in market dynamics therefore affect the supply of general practitioner services to consumers in ways that have unintended consequences. Government policy and regulation changes to the health market at the macro level do not necessarily translate into the uniform desired equity health outcomes for the population at the local level, where private general practices will adjust the supply of services, and thus the size and nature of their catchments, based on maintaining or enhancing their profitability.

\section{Discussion}

This review has highlighted a wide range of diversity in the literature as to how GP catchments can be described, the indicators and measures used to frame the scale of catchments, as well as policy perspectives of different governments as to the role of general practice in provision of primary health care services in the relevant health market. Given the current health reform debate in many countries with a focus on reduced expenditure, there is a pressing need to have accurate empirical data on how and where patients access the services of general practitioners. This may need a re-conceptualisation as to what is understood to be a GP catchment.

There is a need to reconceptualise the concept of place based perspectives and explore the role of time geography Any model that assumes people should be structured only around the residential neighbourhood, treating individuals as if they were static and tied to their residential neighbourhood has significant limitations when considering the behaviours of people in developed countries. It should be more appropriate to integrate people's activity space (e.g. the space about which they travel or move about in the course of their daily activities) when studying the determinants of health inequalities. When these factors are considered, an analysis of catchment patterns of general practitioners should be considered as dynamic and multi-perspective. Studies need to consider how people locate in place; how they move through space in their communities of interest and studies should also consider how they relate to people in space and place. In summary, patient access to general practice health care services should be considered from a range of locational concepts, and not necessarily constrained by their place of residence. Current assumptions about gaps in service provision need to be re-evaluated.

With regard to GP catchment models, the absence of real world data has been identified as a significant weakness of the GIS modelling. Other models, which use real world data such as that developed by Lewis and Longley to map actual GP catchment patterns are extremely important and provide opportunities for health geography to make significant contributions to informing reform on primary health care.

In terms of the inter-relationship between catchments and primary health care issues, the literature identified the role of governments as playing an important role in the regulation of the primary health markets and therefore exerting a strong influence on the types of markets that exist and evolve in primary health care settings. For example, it was identified in England that successive governments have introduced a range of regulations and systems of health delivery to break the monopoly of general practitioners in the primary health market. As noted in the introduction, in the USA, there is widespread debate as to the role of geography in priority setting for future health reform. Thus there is widespread uncertainty as to the effects of these programs on existing markets and catchments of general practice. There is a lack of evidence that such programs will universally provide better access for patients, better health outcomes or reduce health inequalities. It is possible that the effect of government policy will have the perverse result of causing poorer access for patients to GP services. This is an area of research where there is a gap and where there is a need for more research. Promising areas for future research should investigate the spatial and aspatial components of GP catchments, especially at the micro level, and model the effects of changes in the health policy settings of governments on equitable access to services by patients.

\section{Limitations}

There are a number of limitations to this review including the challenge of containing the review study to the catchments of private sector general practice. There were over 1,300 articles identified in the initial search, and from this large cohort, the exclusion criteria required the elimination of many articles in order to meet the 
logistical aims of the review. Inevitably, it is possible that some articles which were excluded should have been included. Inevitably, if journal articles from more countries were included, the quality of the review could have been enhanced.

\section{Conclusions}

This review has examined studies in relation to GP catchments from a range of developed countries. Patient access to general practice health care services should be considered from a range of locational concepts, and not necessarily constrained by their place of residence. An analysis of catchment patterns of general practitioners should be considered as dynamic and multi-perspective. Geographic information systems provide opportunities to contribute valuable methodologies to study these relationships. However, researchers acknowledge that a conceptual framework for the analysis of GP catchments requires access to real world data. The relationship of GP catchments to the health seeking behaviour of consumers and increasingly diversified markets for health services is complex. Recent studies have shown promising developments in the use of real world data, especially from studies in the UK. Understanding the catchment profiles of individual GP surgeries is important if governments are serious about patient choice being a key part of proposed primary health reforms.

\section{Abbreviations}

2SFCA: Two step floating catchment area method; PHA: Practice Health Atlas.

\section{Competing interests}

The author declares that he has no competing interests.

\section{Authors' contribution}

DA designed and formulated the research topic, searched the literatures, analyzed the data and wrote the manuscript. The author read and approved the final manuscript.

\section{Acknowledgements}

Thanks are extended to the anonymous reviewers for their comments on the manuscript draft

Thanks to Dr Mariastella Pulvirenti at Flinders University for guidance in the development of the literature review topic.

Received: 10 April 2014 Accepted: 4 August 2014

Published: 29 August 2014

\section{References}

1. Kaul A, Bhandari P, Walsh T: What does the Dartmouth Atlas have to say about the Politics of the ACA? Health Care Blog 2012, 1.

http:/thehealthcareblog.com/blog/2012/12/27

2. Lewis DJ, Longley PA: Patterns of patient registration with primary health care in the UK National Health Service. Ann Assoc Am Geogr 2012, 102(5):1135-1136.

3. Murphy B: Regarding "National Health and Hospital Reform Commission final report and patient centred suggestions for reform". Aust J Prim Health 2012, 18:2-3.

4. Wiese M, Jolley G, Baum F, Freeman T, Kidd M: Australia's systems of primary healthcare: the need for improved coordination and implications for Medicare locals. Aust Fam Physician 2011, 40:995-999.

5. Daley C, Gubb J: Healthcare Systems. Switzerland: CIVATAS; 2012. updated by Clarke E. (Dec 2011), Bidgood E. (January 2013).
6. Fiegel C: IOM: Target inefficient Medicare doctors, not regions. Am Med Assoc 2013, 1. http://www.amednews.com/apps/ pbcs.dll/personalia? id=cfiegel/.

7. Scandlen G: IOM Debunks Dartmouth. National Centre for Policy Analysis Health Policy Blog; NCPAorg 2013, 1-7.

8. Fisher $\mathrm{E}$, Skinner J: Making sense of geographic variations in health care: the new IOM report. Health Aff Blob 2013, 1-4. http://healthaffairs.org/blog/ 2013/07/24.

9. Lewis DJ, Longley PA: Patterns of patient registration with primary health care in the UK National Health Service. Ann Assoc Am Geogr 2012, 102(5):1135

10. Ansari Z: A review of literature on access to primary health care. Aust J Prim Health 2007, 13(2):93.

11. Bourgueil $Y$, Marek A, Mousques J: Three models of primary care organisation in Europe, Canada, Australia and New Zealand. Questions d'economie de la Sante 2009, 141:1.

12. Bourgueil $Y$, Marek A, Mousques J: Three models of primary care organisation in Europe, Canada, Australia and New Zealand. Questions d'economie de la Sante 2009, 141:1-4.

13. Del Fante $P$, Allan D, Babidge E: The Practice Health Atlas and business modelling opportunities. Aust Fam Physician 2006, 35(1-2):34-38.

14. De Maeseneer J, Willems S, De Sutter A, Van de Geuchte I, Billings M: Primary health care as a strategy for achieving equitable care: a literature review commissioned by the Health Systems Knowledge Network. Health Syst Knowledge Netw 2007, 2-4. http://www.who.int/ social_determinants/thecommission/finalreport/en.

15. De Maeseneer J, Willems S, De Sutter A, Van de Geuchte I, Billings M: Primary health care as a strategy for achieving equitable care: a literature review commissioned by the Health Systems Knowledge Network. Health Syst Knowledge Netw 2007, 3. http://www.who.int/ social_determinants/finalreport/en.

16. Crooks VA, Andrews GJ: Thinking Geographically About Primary Health Care, Chapter 1. In Primary Health Care: People, Practice Place. Ashgate; 2009:12-13.

17. De Maeseneer J, Willems S, De Sutter A, Van de Geuchte I, Billings M: Primary health care as a strategy for achieving equitable care: a literature review commissioned by the Health Systems Knowledge Network. Health Syst Knowledge Netw 2007, 1:1-42. http://www.who.int/ social_determinants/finalreport/en.

18. Crooks VA, Andrews GJ: Thinking Geographically About Primary Health Care, Chapter 1. In Primary Health Care: People, Practice, Place. Ashgate; 2009:11-17.

19. Schuurman N: The effects of Population Density, Physical Distance and Socio-Economic Vulnerability on Access to Primary Health Care in Rural and Remote British Columbia, Canada, Chapter 4. In Primary Health Care: People, Practice, Place. Ashgate; 2009:60.

20. Crooks VA, Andrews GJ: Thinking Geographically About Primary Health Care, Chapter 1. In Primary Health Care: People, Practice, Place. Ashgate; 2009:14.

21. Ansari Z: A review of literature on access to primary health care. Aust J Prim Health 2007, 13(2):80-95.

22. Ansari Z: A review of literature on access to primary health care. Aust $J$ Prim Health 2007, 13(2):83.

23. Penchansky R, Thomas JW: The concept of access: definition and relationship to consumer satisfaction. Med Care 1982, 19(2):127-140.

24. Donabedian A: Models for organizing the delivery of personal health services and criteria for developing them. Milbank Quarterly Fund Quarterly 1972, 50:103-154.

25. Khan AA, Bhardwaj SM: Access to health care. A conceptual framework and its relevance to health care planning. Evaluation and the Health Professions 17(1):60-76

26. Wang F: Measurement, optimisation, and the impact of health care accessibility: a methodological review. Ann Assoc Am Geogr 2012, 102(5):1105

27. Howard P, Feyman Y: Rhetoric and reality - the obamacare evaluation project: access to care and the physician shortage. Med Prog Rep 2013, 15:2-7. Manhattan Institute for Policy Research.

28. Howard P, Feyman Y: Rhetoric and reality - the obamacare evaluation project: access to care and the physician shortage. Med Prog Rep 2013 15:7. Manhattan Institute for Policy Research.

29. Higgs G: A literature review of the use of GIS - based measures of access to health care services. Health Serv Outcome Res Methodol 2004, 5:119-139. 
30. Guagliardo MF: Spatial accessibility of primary care: concepts, methods and challenges. Int J Health Geogr 2004, 3:3.

31. Hugo G, Smailes P, MacGregor C, Fenton M, Brunckhorst D: Defining social catchments in non-metropolitan Australia. Bur Rural Sci 2001, 45:45-49. http://data.daff.gov.au/brsShop/data/12095_social_catch.pdf.

32. Dennis C, Marsland D, Cockett T: Central place practice: shopping centre attractiveness measures, hinterland boundaries and the UK retail hierarchy. J Retail Consum Serv 2002, 9:185-199.

33. Root ED: Moving neighbourhoods and health research forward: using geographic methods to examine the role of spatial scale in neighbourhood effects on health. Ann Assoc Am Geographers 2012, 102(5):986-995.

34. Shortt N, Moore A, Coombes M: Defining regions for locality health care planning: a multidimensional approach. Soc Sci Med 2005, 60(12):2715-2727.

35. Shortt N, Moore A, Coombes M: Defining regions for locality health care planning: a multidimensional approach. Soc Sci Med 2005, 60(12):2725.

36. Bartlet M, Coldefy M, Collin C, Lucas-Gabrielli V: Local Potential Accessibility (LPA): A new measure of accessibility to Private General Practitioners. Questions d'economie de la Sante: Institut de recherche et documentation en economie de la sante; 2012:1-4. No 174. ISBN Local Potential Accessibility (LPA): A new measure of accessibility to Private General Practitioners.

37. Vallee J, Chauvin P: Investigating the effects of medical density on healthseeking behaviours using a multiscale approach to residential and activity spaces. Results from a prospective cohort study in the Paris metropolitan area, France. Int J Health Geogr 2012, 11:54. 26 December 2012.

38. Coldefy M, Lucas-Gabrielli V: The health area, a planning tool for the organisation of care supply and health policy?. Questions d'economie de la Sante: Institut de recherche et documentation en economie de la sante; 2012:1-8. No 175.

39. Rainham D, McDowell L, Krewski D, Sawada M: Conceptualisation the healthscape: contributions of time geography, location technologies and spatial ecology to place and health research. Soc Sci Med 2010, 70(5):668-676.

40. Wiles JL, Rosenberg MW: The Role of Scale in Conceptualising Primary Health Care Practice: Considering Social and Institutional Structures and Systems. In Primary Health Care: People, Practice, Place. Edited by Crooks VA, Andrews GJ. Ashgate Publishing Company; 2009. Chapter 5.

41. Mowbray CT, Woolley ME, Grogan-Kaylor A, Gant LM, Gilster ME, Williams Shanks TR: Neighbourhood research from a spatially oriented strengths perspective. J Commun Psychol 2007, 35(5):667-680.

42. Van Dyck D, Sallis JF, Cardon G, Deforche B, Adams MA, Germia C, De Bourdeaudhuij I: Associations of neighbourhood characteristics with active park use: an observational study in two cities in the USA and Belgium. Int J Health Geogr 2013, 12:26. 7 May 2013.

43. Bell $S$, Wilson $K$, Bissonnette $L$, Shah T: Access to primary health care: does neighbourhood of residence matter? Ann Assoc Am Geogr 2013, 103(1):85-105.

44. Bissonnette L, Wilson K, Shah T1: Neighbourhoods and potential access to health care: the role of spatial and aspatial factors. Health Place 2012, 18(4):841-853.

45. Whynes DK, Thorton P: Measuring concentration in primary care. Health Care Manag Sci 2000, 3:1.

46. Coffee NT, Lockwood T, Hugo G, Paquet C, Howard NJ, Daniel M: Relative residential property value as a socio-economic status indicator for health research. Int J Health Geogr 2013, 12:22. 15 April 2013.

47. McLean G, Guthrie B, Watt G, Gabbay M, O'Donnell CA: Practice postcode versus patient population: a comparison of data sources in England and Scotland. Int J Health Geogr 2008, 7:37. 16 July 2008.

48. Lebel A, Pampalon R, Villeneuve PY: A multi-perspective approach for defining neighbourhood units in the context of a study on health inequalities in the Quebec City region. Int J Health Geogr 2007, 6:27. 5 July 2007.

49. Odoi A, Wray R, Emo M, Birch S, Hutchinson B, Eyles J, Abernathy T: Inequalities in neighbourhood socioeconomic characteristics: potential evidence-base for neighbourhood health planning. Int J Health Geogr 2005, 4:20. 10 August 2005

50. Hawthorne TL, Kwan MP: Using GIS and perceived distance to understand the unequal geographies of healthcare in lower-income urban neighbourhoods. Geogr J 2012, 178:1

51. Speilmann SE, Yoo EH: The spatial dimensions of neighbourhood effects. Soc Sci Med 2009, 68(6):1098-1105.

52. Gordon-Larsen $P$, Nelson MC, Page P, Popkin BM: Inequality in the built environment underlies key health disparities in physical activity and obesity. Pediatrics 2006, 117(2):417-424.

53. Yiannakoulias N, Bland W, Svenson L: Estimating the effect of turn penalties and traffic congestion on measuring spatial accessibility to primary health care. App/ Geogr Volume 2013, 39:172-182.
54. Mobley LR, Root E, Anselin L, Lozano-Gracia N, Koschinsky J: Spatial analysis of elderly access to primary care services. Int J Health Geogr 2006, 5:19. 15 May 2006

55. Wang L: Immigration, ethnicity, and accessibility to culturally diverse family physicians. Health Place 2007, 13(3):656-671

56. Wanga L, Roisman D: Modelling spatial accessibility of immigrants to culturally diverse family physicians. Prof Geographer 2011, 63(1):73-91.

57. Hsin-Chung L: The association of spatial accessibility to health care services with health utilisation and health status among people with disabilities. Ohio Link Electronic Theses and Dissertations Centre; 2010:1-19.

58. McGrail MR, Humphreys JS: Measuring spatial accessibility to primary care in rural areas: improving the effectiveness of the two step floating catchment area method. App/ Geogr 2009, 4:533-541.

59. Barnard DK, Hu W: The population health approach: health GIS as a bridge from theory to practice. Int J Health Geogr 2005, 4:23.

60. Turnbull J, Martin D, Lattimer V, Pope C, Culliford D: Does distance matter? Geographical variation in GP out-of-hours service use: an observational study. Br J Gen Pract 2008, 58(552):471-477.

61. Philips H, Remmen R, De Paepe P, Buylaert W, Van Royen P: Out of hours care: a profile analysis of patients attending the emergency department and the general practitioner on call. BMC Fam Pract 2010, 11:88.

62. Higgs $\mathrm{G}$ : A literature review of the Use of GIS - based measures of access to health care services. Health Serv Outcome Res Methodol 2004, 5:120.

63. McGrail MR: Spatial accessibility of primary health care utilising the two step floating catchment area method: an assessment of recent improvements. Int J Health Geogr 2012, 11:50.

64. Luo W: Using a GIS-based floating catchment method to assess areas with shortage of physicians. Health Place 2004, 10(1):1-11.

65. Wei L, Qi Y: An enhanced two-step floating catchment area (E2SFCA) method for measuring spatial accessibility to primary care physicians. Health Place 2009, 2009(15):1100-1107.

66. Fahui W, Wei L: Assessing spatial and non-spatial factors for healthcare access: towards an integrated approach to defining health professional shortage areas. Health Place 2005, 2009(11):131-146.

67. Roeger SL, Reed R: Equity of access in the spatial distribution of GPs within an Australian metropolitan city. Aust J Prim Health 2010, 16(4):284-290.

68. Yang DH, George R, Mullner R: Comparing GIS-based methods of measuring spatial accessibility to health services. J Med Syst 2006, 30(1):23-32

69. Liu Y, Wong SY, Jin T: Equality of spatial access to primary health services for Singapore's baby boomers. Asian Popul Stud 2009, 5(2):171-188.

70. Wong LY, Heng BH, Cheah JTS, Tan CB: Using spatial accessibility to identify polyclinic service gaps and volume of under-served population in Singapore using Geographic Information System. Int J Health Plann Manag 2012, 27(3):e173-e185.

71. Wang L: Analysing spatial accessibility to health care: a case study of access by different immigrant groups to primary care physicians in Toronto. Ann GIS 2011, 17(4):237-251.

72. Bagheri N: Modelling accessibility to primary care using a spatial accessibility index and a need index. Hawail' J Public Health1 2008, 1(1):14-27.

73. MCGrail MR, Humphreys JS: A new index of access to primary care services in rural areas. Aust N Z J Public Health 2009, 33(5):418-423.

74. Russell DJ, Humphreys JS, Ward B, Chisholm MC, Buykx P, McGrail M, Wakerman J: Helping policy-makers address rural health access problems. Aust J Rural Health Alliance 2013, 21(2):61-71.

75. Escobar F, Williamson I, Waters E, Green J, Hugo G, Rudd C: The Role of GIS in Management of Primary Health Care Services. Christchurch NZ: Presented at 25th Annual Conference of the Australian Urban and Regional Information Systems Assoc; 1997.

76. Samarasundera E, Walsh T, Cheng T, Koenig A, Jattansingh K, Solijak M: Methods and tools for geographical mapping in primary health care. Prim Health Care Res Dev 2012, 13(01):10-21.

77. Drackley A, Newbold KB, Taylor C: Defining socially-based spatial boundaries in the region of peel, Ontario. Canada. Int J Health Geogr 2011, 10:38.

78. Luo W, Whippo T: Variable catchment sizes for the two-step floating catchment area (2SFCA) method. Health Place 2012, 18(4):789-795.

79. Langford M, Higgs G: Measuring potential access to primary healthcare services: the influence of alternative spatial representations of population. Prof Geography 2006, 58(3):294-306.

80. Delamater PL, Messina JP, Shortridge A, Grady SC: Measuring geographic access to health care: raster and network methods. Int J Health Geogr 2012, $11: 15$ 
81. Bates A: The development of a "Postcode Best Fit" methodology for producing Population Estimates for different geographies. Popul Trends 2008, 133:28-34

82. Foley R, Charlton MC, Stewart A: GIS in Health and Social Care Planning. In Handbook of Theoretical and Quantitative Geography. Lausanne: Univ de Lausanne-Faculte des geosciences et de l'environnement; 2012:73-115.

83. Guagliardo MF: Spatial accessibility of primary care: concepts, methods and challenges. Int J Health Geogr 2004, 3(3):10.

84. Salze P, Banos A, Oppert JM, Charreire H, Casey R, Simon C, Chaix B, Badariotti D, Weber C: Estimating spatial accessibility to facilities on the regional scale: an extended commuting-based interaction potential model. Int J Health Geogr 2011, 10:2.

85. Boulos M: Towards evidence-based. GIS-driven national spatial health information infrastructure and surveillance services in the United Kingdom. Int J Health Geogr 2004, 3:1.

86. Farry $\mathrm{P}$, Thompson $\mathrm{R}$, Robertson $\mathrm{H}$, Benwell $\mathrm{G}$, Williamson M: The role of GIS in supporting evidence-based rural health service planning and evaluation: A New Zealand case study. NZFP 2008, 15:6

87. Taylor DM, Yeager VA, Ouimet C, Menachemi N: Using GIS for administrative decision-making in a local public health setting. Public Health Rep 2012, 127:347-353.

88. Liu JJ, Bellamy G, Barnet B, Weng S: Bypass of local primary care in rural counties: effect of patient and community characteristics. Ann Fam Med 2008, 6(2):124-130

89. Kroneman MW, Maarse $\mathrm{H}$, Van der Zee J: Direct access in primary care and patient satisfaction: a European study. Health Policy 2006, 76(1):72-79.

90. Mold JW, Fryer GE, Roberts AM: When do older patients change primary care physicians? J Am Board Fam Pract 2004, 17(6):453-460.

91. Comber AJ, Brunsdon C, Radburn R: A spatial analysis of variations in health access: linking geography, socio-economic status and access perceptions. Int J Health Geogr 2011, 10:44

92. Arora R, Singer J, Arora A: Influence of key variables on the patients choice of a physician. Qual Manage Health Care 2004, 13(3):166-173.

93. Mallya G, Pollack CE, Polsky D: Are primary care physicians ready to practice in a consumer-driven environment? Am J Manag Care 2008, 14(10):661-668.

94. Gene-Badia J, Ascaso C, Escaramis-Babiano G, Catalan-Ramos A, Pujoi-Ribera E, Samprietro-Colom L: Population and primary health-care team characteristics explain the quality of service. Health Policy 2008, 86(2-3):335-344.

95. Greener I: Are the assumptions underlying patients choice realistic? A review of the evidence. Br Med Bull 2007, 83:249-258.

96. Busato A, Donges A, Herren S, Widmer M, Marian F: Health status and health care utilisation of patients in complementary and conventional primary care in Switzerland - an observational study. Fam Prac Adv Access 2005, 23(1):1-6.

97. Landon BE, Normand SL, Frank R, McNeil BJ: Characteristics of medical practices in three developed managed care markets. Health Serv Res 2005, 40(3):675-696.

98. McRae I: Doctors at Work: Determinants of the supply and demand in the Australian GP market. ANU: Ph D thesis; 2008:183-184.

99. Busato A, Matter $P$, Kunzi B: Factors related to treatment intensity in Swiss primary care. BMC Health Serv Res 2009, 9:49.

100. Busato A, Kunzi B: Primary care physician supply and other determinants of health care utilisation: the case of Switzerland. BMC Health Serv Res 2008, 8:8.

101. Punka H: Primary care strategies for 3 market types. In Becker's Hospital Review. 2012:1. http://www.beckershospitalreview.com/hospital-physicianrelationships/ building-a-competitive-model.

102. Sofianopoulou E, Rushton S, Rubin G, Pless-Mulloli T: Defining GP practice areas based on true service utilisation. Health Place 2012, 18(6):1248-1254.

103. Fulop G, Kopetsch T, Schope P: Catchment areas of medical practices and the role played by geographical distance in the patient's choice of doctor. Springer-Verlag 2011, 46(3):691-706. Geographics December 2009). and The Annals of Regional Science.

104. Rudavsky R, Pollack CE, Mehrotra A: The geographic distribution, ownership, process, and scope of practice at retail clinics. Am Coll Phys Intern Med 2009, 151:5

105. Reid RO, Ashwood JS, Friedberg MW, Weber ES, Setodji CM, Mehrotra A: Retail clinic visits and receipt of primary care. J Gen Intern Med 2013, 28(4):504-512.

106. Kissinger M: Retail health clinics drive innovation into primary care practice. J Med Prac Manag 2008, 23(5):314-319.

107. Gingrich J: Making markets in the welfare state: the politics of varying market reforms. Cambridge: Cambridge University Press; 2011.
108. Pollock A, Price D, Viebrock E, Miller E, Watt G: The market in primary care. BMJ 2007, 6:335-475

109. Pollock AM, Price D: Loss of population data sources when health systems are not responsible for geographically defined populations: Implications of the Health and Social care Act of 2012 England. Evid Based Med 2014, 19(1):4-5.

110. Ellins J, Ham C, Parker H: Opening up the primary medical care market. BMJ 2009, 338:b1127.

111. Roland M, Guthrie B, Thorne C: Primary medical care in the united kingdom. J Am Board Fam Pract 2012, 25(Suppl/):S6-S11.

112. Lewis $R Q$, Thorlby R: Liberalising the health care market: the new government's ambition for the English National Health Service. Int $J$ Health Serv 2011, 41(3):565-574.

113. McDonald R: Market reforms in English primary medical care: medicine, habitus and the public sphere. Sociol Health IIIn 2009, 31(5):659-672.

114. Turner D, Salway S, Mir G, Ellison G, Skinner J, Carter L, Bostan B: Prospects for progress on health inequalities in England in the post-primary care trust era: professional views on challenges, risks and opportunities. BMC Public Health 2013, 13:274.

115. Stange K: How does provider supply and regulation influence health care markets? Evidence from nurse practitioners and physicians assistants. NBER Working Paper No. 19172. The National Bureau of Economic Research; 2013.

116. Bernstein $A B$, Gauthier AK: Defining competition in markets: why and how? Health Serv Res 1998, 33(5 Pt 2):1421-1438.

117. McDonald J, Ollerenshaw A: Priority setting in primary health care: a framework for local catchments. Rural Remote Health 2011, 11(2):1714.

118. Howell B: Restructuring Primary Health Care Markets in New Zealand: from Welfare Benefits to Insurance Markets. Aust N Z Health Policy 2005, 2:20.

119. Gresenz CR, Rogowski J, Escarce JJ: Health care markets, the safety net, and utilisation of care among the uninsured. Health Serv Res 2007, 42(1 Pt 1):239-264.

120. Mwachofi A, Al-Asaf AF: Health care market deviations from the ideal market. Sultan Qaboos Univ Med J 2011, 11(3):328-337.

121. Maljers J: Market forces inevitable in health care. Ned Tijdschr Geneeskd 2006, 150(18):1014.

122. Porell FW, Liu K, Brungo DP: Agency and market area factors affecting home health agency supply changes. Health Serv Res Oct 2006, 41(5):1847-1875

123. Gambie M: Building a competitive model for market share and primary care. In Becker's Hospital Review. 2012:1. http://www.beckershospitalreview. com/hospital-physicianrelationships/building-a-competitive-model.

124. Allan D, Del Fante P, Reeves J, Stratford D, Miller J: How can spatial analysis inform the workforce gaps in supply and demand for health services?. Australia: Presentation at the Primary Health Research and Information Service Conference (PHC RIS); 2010

\section{doi:10.1186/1476-072X-13-32}

Cite this article as: Allan: Catchments of general practice in different countries- a literature review. International Journal of Health Geographics 2014 13:32

\section{Submit your next manuscript to BioMed Central and take full advantage of:}

- Convenient online submission

- Thorough peer review

- No space constraints or color figure charges

- Immediate publication on acceptance

- Inclusion in PubMed, CAS, Scopus and Google Scholar

- Research which is freely available for redistribution 